\title{
THE TYPE OF VASCULAR ACCESS AND THE EFFECTIVENESS OF HAEMODIALYSIS
}

\author{
Agata Cieniawa
}

Department of Nephrology, University Hospital, Krakow, Poland

Authors' contribution:

A. Study design/planning • B. Data collection/entry $\bullet$ C. Data analysis/statistics $\bullet$ D. Data

interpretation $\bullet$ E. Preparation of manuscript $\bullet$ F. Literature analysis/search $\bullet$ G. Funds collection

\author{
Address for correspondence: \\ Agata Cieniawa \\ Department of Nephrology \\ University Hospital \\ 36 Kopernika St., 31-501 Krakow, Poland \\ e-mail: agataciesielczyk@onet.pl \\ SUBMITTED: 19.10 .2020 \\ ACCEPTED: 18.12 .2020 \\ DOI: https://doi.org/10.5114/ppiel.2020.103536
}

\begin{abstract}
Introduction: Chronic kidney disease has been perceived in recent years as a disease of civilisation. Patients with stage 5 or 4 renal failure require renal replacement therapy. Ninety per cent of patients with renal failure are treated using haemodialysis. In order to perform extracorporeal blood purification procedures, it is necessary to establish a vascular access for the patient. The efficiency of haemodialysis can be determined based on the urea reduction rate and dialyser's urea clearance. One of the main factors influencing the adequacy of dialysis is the type of vascular access.

Aim of the study: To ascertain whether the type of vascular access influences the effectiveness of haemodialysis. Material and methods: The study included 61 patients dialysed at the University Hospital in Cracow in the period from December 2018 to February 2019. The study compared potassium values before and after haemodialysis, the degree of urea removal, and the urea clearance of the dialyser.

Results: The best results were obtained by patients dialysed using an arteriovenous fistula; for those patients the urea reduction ratio (URR) was 0.7 and the $\mathrm{Kt} / \mathrm{V}$ was 1.7; the worst values were found for patients dialysed using a Gero-trex artificial vessel.

Conclusions: The type of vascular access affects the effectiveness of haemodialysis.

Key words: haemodialysis, vascular access, efficiency.
\end{abstract}

\section{INTRODUCTION}

Based on epidemiology data on chronic kidney disease (CKD), the occurrence rate oscillates between $9 \%$ and $15 \%$ of the studied population, which allows conclusion that about $10-11 \%$ of the global population has a certain stage of this condition. The results of the worldwide Global Burden of Disease 2017 research show that in 2017 the disease was present in about 697.5 million people (9.1\%), as compared to 549.2 million in 2007 , i.e. the incidence increased by $27 \%$, and there were 1.2 million deaths due to this condition, as compared to 920 thousand in 2007 (increase by 34\%) $[1,2]$. In Poland, based on the NFZ (National Health Fund) registry, as well as epidemiology data, it is estimated that about 4.3 million people suffer from CKD at different stages, with about 15 thousand patients requiring renal replacement therapy each year [3]. Haemodialysis is a renal replacement therapy broadly used worldwide. Each dialysis should provide adequate elimination of medium- and small-molecule uraemic toxins [4]. The best way to determine whether the dialysis technique used in a given site is effective is to analyse patient survival, which depends on various factors, including age, comorbidities, the underlying cause of renal failure, therapy compliance, and the proficiency of the healthcare personnel taking care of the patient [5]. Dialysis efficiency can be determined based on urea reduction rate (URR) and urea clearance of the dialyser (Kt/V). These values are regularly calculated in most dialysis centres after patient blood tests performed monthly, where morphology parameters, such as electrolytes, including urea and potassium before and after the completed dialysis, are assayed. By assaying these parameters, one may check whether the dialysis parameters are suitable for the patient $[6,7]$. Some factors that must be considered when adjusting the dialysis settings for the patient, include time, frequency of dialysis, type of biocompatible materials used, balance of calcium-magnesium metabolism, anaemia equilibration, and, most importantly, choosing the correct type of vascular access. Adequate dialysis is performed at least 3 times a week, and a single procedure is at least 4 hours long. Indices that show dialysis efficiency includes a urea di- 
alysis rate that should be at least $70 \%$. The second index is Kt/V, which should be above $1.3[8,11]$.

\section{AIM OF THE STUDY}

To ascertain whether the type of vascular access influences the effectiveness of haemodialysis.

\section{MATERIAL AND METHODS}

The research was retrospective. The study used the method of analysing medical records of patients undergoing dialysis at the University Hospital in the Department of Haemodialysis. Approval for the conduct of this study was obtained from the head of the Nephrology Clinic: Prof. Marek Kuźniewski, MD, PhD, and the head of the Department: Grzegorz Chmiel, $\mathrm{MD}, \mathrm{PhD}$. The study was conducted in concordance with the Declaration of Helsinki. The tools used included the following: discharge summaries, procedure protocols after exposure of vascular access, dialysis cards and results of laboratory tests from a period of 3 months (December, January, February) in $2018 / 2019$. In order to verify whether various vascular access types influence the haemodialysis efficiency, the basic descriptive analyses were calculated as well as single-factor variance analysis. Tuckey's multiple post-hoc comparison test was also used. For variables measured in the nominal scale, structure numbers and indices - percentage values - were calculated. For all analyses, a significance value of 0.05 was adopted. The Fisher Snedecor test was used for the analysis - it examines whether the differences between the data are significant.

\section{RESULTS}

The study was conducted at the University Hospital in a group of 61 haemodialysed patients. In the study group 38 (61.67\%) were men and 23 (38.33\%) were women. Among 61 patients with grade 5 renal

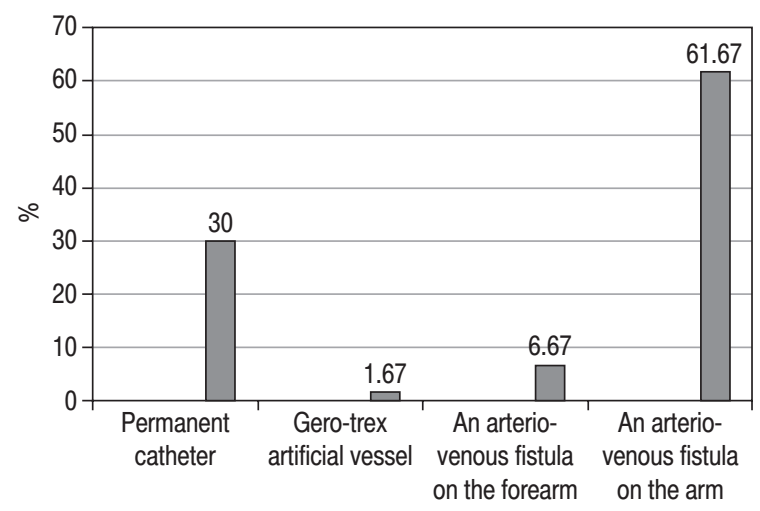

Figure 1. The type of vascular access with which the patient was dialysed failure treated with haemodialysis, in 37 (i.e. 61.67\%) the procedure was performed using arterio-venous shunt in the forearm. In 18 (i.e. 30\%) patients, haemodialysis was performed using an indwelling catheter; in 4 (i.e. 6.67\%) patients, arterio-venous shunt in the arm was used; only 1 (i.e. 1.67\%) patient had a Gerotrex type implanted artificial vessel (Fig. 1).

The analyses that compared vascular access types with results of laboratory tests performed in December 2018 showed that the vascular access type influences the haemodialysis adequacy. Based on the analysis of urea removal rate and distribution volume clearance, the most effective dialysis was obtained via the arterio-venous shunt in the arm, and the least effective dialysis was that performed using the artificial vessel. In terms of potassium removal rate, dialysis using the indwelling catheter proved most effective (see Table 1).

Table 2 shows that there is a statistically significant relationship between the variety of vascular accesses and the value of iron $(p=0.03)$, while there is no statistically significant difference between the other variables depending on the vascular access used $(p>0.05)$.

Statistical analyses performed based on laboratory tests in 61 patients haemodialysed in January 2019 provided results similar to those obtained earlier. The most effective dialysis was that via the arterio-venous shunt in the arm; slightly worse results were found in patients haemodialysed using the arterio-venous shunt in the forearm. The worst results were found for the patient haemodialysed using the artificial vessel (Table 3).

Analysing the results from January, a statistically significant difference was shown between the use of a particular type of vascular access and the value of iron $(p=0.001)$ and potassium after haemodialysis $(p=0.01)$. However, there is no statistically significant difference between the other variables depending on the given vascular access used $(p>0.05)$ (Table 4).

The analysis shown in Table 4 allowed us to conclude that a variety of venous access types significantly influence the results of the potassium variable after haemodialysis $(p=0.01)$. To determine the groups with the largest significant differences, Tuckey's multiple post-hoc comparison tests were applied.

Tuckey's post-hoc multiple comparison test was used for a more detailed comparison of how particular vascular accesses differentiated iron values, as can be seen in Table 5. The analysis shows that in the group with an arteriovenous fistula on the arm, the iron level was statistically significantly higher than in the group with an arteriovenous fistula on the forearm $(p=0.04)$. In the arm arteriovenous fistula group, the average iron level was $M=16.288$, while in the forearm arteriovenous fistula group, the average iron level was $M=9.4841$. In the case of other artificial uses of the Gero-trex vessel or permanent catheter, 
Table 1. Basic descriptive statistics depending on vascular access - December

\begin{tabular}{|c|c|c|c|c|c|}
\hline Variables & Statistics & $\begin{array}{c}\text { Arteriovenous } \\
\text { fistula at the } \\
\text { lower arm }\end{array}$ & $\begin{array}{c}\text { Arteriovenous } \\
\text { fistula at the } \\
\text { upper arm }\end{array}$ & $\begin{array}{c}\text { Gero-trex } \\
\text { artificial vessel }\end{array}$ & $\begin{array}{l}\text { Permanent } \\
\text { catheter }\end{array}$ \\
\hline \multirow[t]{2}{*}{ Iron value $(\mu \mathrm{mol} / \mathrm{l})$} & M & 9.484 & 16.288 & 16.510 & 11.436 \\
\hline & SD & 3.170 & 11.654 & & 5.478 \\
\hline \multirow{2}{*}{$\begin{array}{l}\text { Urea level before hemodialysis } \\
(\mathrm{mmol} / \mathrm{l})\end{array}$} & M & 22.062 & 25.950 & 22.900 & 22.100 \\
\hline & SD & 5.031 & 3.252 & & 6.310 \\
\hline \multirow{2}{*}{$\begin{array}{l}\text { Urea level after hemodialysis } \\
(\mathrm{mmol} / \mathrm{l})\end{array}$} & M & 6.419 & 7.158 & 7.400 & 7.333 \\
\hline & SD & 2.265 & 2.112 & & 4.439 \\
\hline \multirow[t]{2}{*}{ Delta urea level (mmol/l) } & M & 15.643 & 18.793 & 15.500 & 14.767 \\
\hline & SD & 3.827 & 2.279 & & 3.196 \\
\hline \multirow{2}{*}{$\begin{array}{l}\text { Potassium values before } \\
\text { hemodialysis }(\mathrm{mmol} / \mathrm{l})\end{array}$} & M & 5.411 & 5.723 & 4.390 & 4.890 \\
\hline & SD & 0.667 & 0.577 & & 0.923 \\
\hline \multirow{2}{*}{$\begin{array}{l}\text { Potassium values after } \\
\text { hemodialysis }(\mathrm{mmol} / \mathrm{l})\end{array}$} & M & 4.017 & 4.420 & 3.230 & 3.972 \\
\hline & SD & 0.397 & 0.667 & & 0.468 \\
\hline \multirow[t]{2}{*}{ Delta potassium (mmol/l) } & M & 1.394 & 1.303 & 1.160 & 0.918 \\
\hline & SD & 0.562 & 0.512 & & 0.654 \\
\hline \multirow[t]{2}{*}{$\mathrm{Kt} / \mathrm{V}$} & M & 1.525 & 1.643 & 1.326 & 1.443 \\
\hline & SD & 0.311 & 0.266 & & 0.250 \\
\hline \multirow[t]{2}{*}{ Urea reduction ratio } & M & 0.710 & 0.726 & 0.677 & 0.681 \\
\hline & SD & 0.075 & 0.057 & & 0.081 \\
\hline
\end{tabular}

$M-$ median SD - standard deviation

no statistically significant differences were found at $p>0.05$ (Table 5).

Data analysis allowed us to conclude that in the group with the arterio-venous shunt in the arm, the potassium level after the haemodialysis was statistically significantly higher than in the case of the indwelling catheter $(p=0.044)$. In the case of the other interactions, statistically significant differences were not found $(p>0.05)$.

The statistical analyses performed for chosen patients haemodialysed in February 2019 confirmed that the best haemodialysis results were obtained for patients with arterio-venous shunts in the arm, and slightly worse results were found for patients dialysed using the indwelling catheter and using the artificial vessel (Table 6).

Table 7 presents the results of the analysis comparing the influence of the variety of vascular accesses on the effectiveness of haemodialysis. It was found that the diversity of vascular accesses significantly differentiated only the results of the variable iron value $(p=0.002)$, while it did not differentiate the other values $(p>0.05)$.

\section{DISCUSSION}

The performed study shows that vascular access influences the efficiency of the performed haemodialysis. Based on statistical analyses, it was unequivo-
Table 2. Variation analysis. The marked effects are significant with $p<0.05$

\begin{tabular}{lcc}
\hline Variables & $F$ & $p$ \\
\hline Iron value $(\mu \mathrm{mol} / \mathrm{l})$ & 3.25 & 0.03 \\
\hline Urea level before hemodialysis $(\mathrm{mmol} / \mathrm{l})$ & 0.65 & 0.59 \\
\hline Urea level after hemodialysis $(\mathrm{mmol} / \mathrm{l})$ & 0.39 & 0.76 \\
\hline Deltaurea level $(\mathrm{mmol} / \mathrm{l})$ & 1.39 & 0.26 \\
\hline $\begin{array}{l}\text { Potassium values before hemodialysis } \\
\text { (mmol/l) }\end{array}$ & 2.28 & 0.08 \\
\hline $\begin{array}{l}\text { Potassium values after hemodialysis } \\
\text { (mmol/l) }\end{array}$ & 2.27 & 0.09 \\
\hline Delta potassium $(\mathrm{mmol} / \mathrm{l})$ & 2.66 & 0.06 \\
\hline Kt/V & 0.75 & 0.53 \\
\hline Urea reduction ratio & 0.78 & 0.51 \\
\hline$p-$ coefficient of statistical significance, $F-$ Fisher Snedecor's test
\end{tabular}

cally found that the haemodialysis performed using an arterio-venous shunt made from the patient's own vessels is the most efficient. In the study group, $61.67 \%$ of patients were dialysed using an arteriovenous shunt in the arm. This group obtained the best results. Mean median Kt/V value in patients with arterio-venous shunt in the arm was 1.6-1.7. In the group of patients with arterio-venous shunt in the forearm, which comprised $6.67 \%$ of the study population, Kt/V was 1.5-1.6. Patients with indwelling 
Table 3. Basic descriptive statistics depending on vascular access - January

\begin{tabular}{|c|c|c|c|c|c|}
\hline Variables & Statistics & $\begin{array}{l}\text { Arteriovenous } \\
\text { fistula at the } \\
\text { lower arm }\end{array}$ & $\begin{array}{c}\text { Arteriovenous } \\
\text { fistula at the } \\
\text { upper arm }\end{array}$ & $\begin{array}{c}\text { Gero-trex } \\
\text { artificial vessel }\end{array}$ & $\begin{array}{l}\text { Permanent } \\
\text { catheter }\end{array}$ \\
\hline \multirow[t]{2}{*}{ Iron value $(\mu \mathrm{mol} / \mathrm{l})$} & M & 12.224 & 17.550 & 30.200 & 11.338 \\
\hline & SD & 4.775 & 10.366 & & 3.903 \\
\hline \multirow{2}{*}{$\begin{array}{l}\text { Urea level before hemodialysis } \\
(\mathrm{mmol} / \mathrm{l})\end{array}$} & M & 22.993 & 27.100 & 21.600 & 21.011 \\
\hline & SD & 4.510 & 2.486 & & 6.094 \\
\hline \multirow{2}{*}{$\begin{array}{l}\text { Urea level after hemodialysis } \\
(\mathrm{mmol} / \mathrm{l})\end{array}$} & M & 6.632 & 7.325 & 6.900 & 6.439 \\
\hline & SD & 2.089 & 1.193 & & 2.936 \\
\hline \multirow[t]{2}{*}{ Delta urea level $(\mathrm{mmol} / \mathrm{l})$} & M & 16.360 & 19.775 & 14.700 & 14.572 \\
\hline & SD & 3.402 & 3.308 & & 4.036 \\
\hline \multirow{2}{*}{$\begin{array}{l}\text { Potassium values before } \\
\text { hemodialysis }(\mathrm{mmol} / \mathrm{l})\end{array}$} & M & 5.680 & 6.090 & 4.250 & 5.431 \\
\hline & SD & 0.726 & 0.725 & & 0.959 \\
\hline \multirow{2}{*}{$\begin{array}{l}\text { Potassium values after } \\
\text { hemodialysis }(\mathrm{mmol} / \mathrm{l})\end{array}$} & M & 4.182 & 5.125 & 3.960 & 4.152 \\
\hline & SD & 0.425 & 1.125 & & 0.501 \\
\hline \multirow[t]{2}{*}{ Delta potassium $(\mathrm{mmol} / \mathrm{l})$} & M & 1.498 & 0.965 & 0.290 & 1.279 \\
\hline & SD & 0.662 & 1.610 & & 0.927 \\
\hline \multirow[t]{2}{*}{$\mathrm{Kt} / \mathrm{V}$} & M & 1.550 & 1.703 & 1.339 & 1.516 \\
\hline & SD & 0.324 & 0.282 & & 0.273 \\
\hline \multirow[t]{2}{*}{ Urea reduction ratio } & M & 0.712 & 0.726 & 0.681 & 0.700 \\
\hline & SD & 0.060 & 0.059 & & 0.075 \\
\hline
\end{tabular}

$M-$ median SD - standard deviation

Table 4. Variation analysis. The marked effects are significant with $p<0.05$

\begin{tabular}{lcc}
\hline Variables & $F$ & $p$ \\
\hline Iron value $(\mu \mathrm{mol} / \mathrm{l})$ & 5.88 & 0.001 \\
\hline Urea level before hemodialysis $(\mathrm{mmol} / \mathrm{l})$ & 1.80 & 0.16 \\
\hline Urea level after hemodialysis $(\mathrm{mmol} / \mathrm{l})$ & 0.16 & 0.92 \\
\hline Deltaurea level $(\mathrm{mmol} / \mathrm{l})$ & 2.57 & 0.06 \\
\hline $\begin{array}{l}\text { Potassium values before hemodialysis } \\
\text { (mmol/l) }\end{array}$ & 1.82 & 0.15 \\
\hline $\begin{array}{l}\text { Potassium values after hemodialysis } \\
\text { (mmol/l) }\end{array}$ & 4.45 & 0.01 \\
\hline $\begin{array}{l}\text { Delta potassium (mmol/l) } \\
\text { Kt/V }\end{array}$ & 1.26 & 0.30 \\
\hline Urea reduction ratio & 0.56 & 0.64 \\
\hline$p-$ coefficient of statistical significance, $F$ - Fisher Snedecor's test
\end{tabular}

catheter comprised $30 \%$ of the study population; in this group the mean $\mathrm{Kt} / \mathrm{V}$ was 1.4-1.5. The smallest group comprised 1 patient (1.67\%) dialysed using an artificial vessel; here, the mean $\mathrm{Kt} / \mathrm{V}$ values were the lowest, at 1.3. According to recommendations given in the source data, Kt/V in dialysed patients should be 1.3-1.4 [12].

All study patients had good results confirming that the procedure of systemic clearance was adequately individually chosen for each of them. Patients with organism detoxication via shunts had higher values than the recommended ones. A study was performed in 2009 at the dialysis centre of the Public Regional Hospital in Suwałki, where dialysis adequacy was assessed using the Kt/V ratio. The study included 106 patients dialysed using an arterio-venous shunt and indwelling catheter. Blood flow and chemistry param-

Table 5. Tuckey's post-hoc multiple comparison test for variable post-haemodialysis potassium

\begin{tabular}{lcccc}
\hline Type of vascular access & $\{1\}$ & $\{2\}$ & $\{3\}$ & $\{4\}$ \\
& $M=4.1824$ & $\mathbf{M}=5.1250$ & $\mathbf{M}=3.9600$ & $\mathbf{M}=4.1517$ \\
\hline Arteriovenous fistula on the forearm $\{1\}$ & & 0.054 & 0.990 & 0.998 \\
\hline Arteriovenous fistula on the arm $\{2\}$ & 0.054 & & 0.378 & 0.044 \\
\hline Gero-trex artificial vessel $\{3\}$ & 0.990 & 0.378 & & 0.993 \\
\hline Permanent catheter $\{4\}$ & 0.998 & 0.044 & 0.993 & \\
\hline
\end{tabular}

$M$-arithmetic mean 
Table 6. Basic descriptive statistics depending on vascular access - February

\begin{tabular}{|c|c|c|c|c|c|}
\hline Variables & Statistics & $\begin{array}{c}\text { Arteriovenous } \\
\text { fistula at the } \\
\text { lower arm }\end{array}$ & $\begin{array}{c}\text { Arteriovenous } \\
\text { fistula at the } \\
\text { upper arm }\end{array}$ & $\begin{array}{c}\text { Gero-trex } \\
\text { artificial vessel }\end{array}$ & $\begin{array}{l}\text { Permanent } \\
\text { catheter }\end{array}$ \\
\hline \multirow[t]{2}{*}{ Iron value $(\mu \mathrm{mol} / \mathrm{l})$} & M & 11.470 & 17.498 & 24.310 & 11.103 \\
\hline & SD & 3.345 & 10.076 & & 4.263 \\
\hline \multirow{2}{*}{$\begin{array}{l}\text { Urea level before hemodialysis } \\
(\mathrm{mmol} / \mathrm{l})\end{array}$} & M & 21.581 & 23.300 & 20.900 & 20.186 \\
\hline & SD & 5.007 & 3.710 & & 4.764 \\
\hline \multirow{2}{*}{$\begin{array}{l}\text { Urea level after hemodialysis } \\
(\mathrm{mmol} / \mathrm{l})\end{array}$} & M & 6.635 & 6.775 & 7.400 & 5.984 \\
\hline & SD & 2.248 & 2.435 & & 2.199 \\
\hline \multirow[t]{2}{*}{ Delta urea level (mmol/l) } & $M$ & 14.946 & 16.525 & 13.500 & 14.202 \\
\hline & SD & 3.654 & 1.907 & & 3.360 \\
\hline \multirow{2}{*}{$\begin{array}{l}\text { Potassium values before } \\
\text { hemodialysis }(\mathrm{mmol} / \mathrm{l})\end{array}$} & M & 5.410 & 5.120 & 5.260 & 5.103 \\
\hline & SD & 0.660 & 0.506 & & 0.800 \\
\hline \multirow{2}{*}{$\begin{array}{l}\text { Potassium values after } \\
\text { hemodialysis }(\mathrm{mmol} / \mathrm{l})\end{array}$} & $M$ & 4.080 & 4.068 & 3.750 & 4.037 \\
\hline & SD & 0.417 & 0.283 & & 0.450 \\
\hline \multirow[t]{2}{*}{ Delta potassium (mmol/l) } & $M$ & 1.330 & 1.053 & 1.510 & 1.066 \\
\hline & SD & 0.601 & 0.706 & & 0.569 \\
\hline \multirow[t]{2}{*}{$\mathrm{Kt} / \mathrm{V}$} & $M$ & 1.479 & 1.597 & 1.221 & 1.534 \\
\hline & SD & 0.322 & 0.350 & & 0.241 \\
\hline \multirow[t]{2}{*}{ Urea reduction ratio } & M & 0.694 & 0.715 & 0.646 & 0.706 \\
\hline & SD & 0.076 & 0.071 & & 0.063 \\
\hline
\end{tabular}

$M-$ median SD - standard deviation

eters were assayed; these analyses were the basis for assessment of dialysis adequacy. Better blood flow was found in patients dialysed via vascular access made using the patient's own vessels. The blood flow was slightly worse in patients with an indwelling catheter. In the study group, no relationship between the type of vascular access and Kt/V value was found [13]. In a work by Ifudu et al., comparing the efficiency of dialysis in patients with naturally made vascular access and patients with implanted artificial PTFE prostheses, the authors concluded that artificial vessels do not allow a more efficient dialysis [14]. The results obtained in the study, similarly to the KDOQI recommendations, indicate that arterio-venous shunt made from the patient's own vessels is the best type of vascular access, which should be used to dialyse patients. KDOQI indicates that up to $90 \%$ of patients should be dialysed using such access. It must be noted, however, that for various reasons, such as age or comorbidities, it is not always possible to make a permanent vascular access. Vascular access must always be chosen individually for each patient [15].

\section{CONCLUSIONS}

Analysis of medical records performed between December 2018 and February 2019 has shown that the vascular access type influences the haemodialysis efficiency in patients dialysed at the University
Table 7. Variation analysis. The marked effects are significant with $p<0.05$

\begin{tabular}{|c|c|c|}
\hline Variables & $F$ & $p$ \\
\hline Iron value $(\mu \mathrm{mol} / \mathrm{l})$ & 5.46 & 0.002 \\
\hline Urea level before hemodialysis (mmol/l) & 0.58 & 0.63 \\
\hline Urea level after hemodialysis (mmol/l) & 0.43 & 0.73 \\
\hline Deltaurea level (mmol/l) & 0.57 & 0.64 \\
\hline $\begin{array}{l}\text { Potassium values before hemodialysis } \\
(\mathrm{mmol} / \mathrm{l})\end{array}$ & 0.87 & 0.46 \\
\hline $\begin{array}{l}\text { Potassium values after hemodialysis } \\
(\mathrm{mmol} / \mathrm{l})\end{array}$ & 0.23 & 0.88 \\
\hline Delta potassium (mmol/l) & 0.98 & 0.41 \\
\hline $\mathrm{Kt} / \mathrm{V}$ & 0.56 & 0.64 \\
\hline Urea reduction ratio & 0.37 & 0.77 \\
\hline
\end{tabular}

$p$-coefficient of statistical significance, $F$ - Fisher Snedecor's test

Hospital in Cracow. The vascular access type influences the haemodialysis efficiency; the best results were obtained for patients dialysed using arteriovenous shunts, while the worst results were seen in patients haemodialysed using the artificial vessels. The analyses show that in the group of patients with an arteriovenous fistula in the arm, the iron level was statistically significantly higher than in the group of patients with an arteriovenous fistula in the forearm. In the group with an arteriovenous fistula in the arm, 
the average iron level was $M=16.288$, while in the group with an arterio-venous fistula in the forearm, the average iron level was $M=9.4841$, which was statistically significantly higher than in the case of permanent catheter $(p=0.044)$. In the case of other interactions, no statistically significant differences were found $(p>0.05)$.

\section{Disclosure}

The author declares no conflict of interest.

\section{References}

1. Durlik M, Gellert R, Małgorzewicz S. Report 2019. National study of nephrological patients. Nephrological Forum 2020; 13: 149-163.

2. Ciechanowski K. Assessment of kidney function. In: Myśliwiec M (Ed.). Wielka Interna. $2^{\text {nd }}$ ed. Nephrology. Medical Tribune Polska, Warsaw 2017; 20-31.

3. Rutkowski P, Rutkowskiej B. Basic information on chronic kidney disease. In: Myśliwiec M (Ed.). Wielka Interna. $2^{\text {nd }}$ ed. Nephrology. Medical Tribune Polska, Warsaw 2017; 340-341.

4. Sułowicz W. Practical aspects of dialysis quality assessment. Nephrological Forum 2010; 3: 185-192.

5. Gellert R. Hemodialysis and other blood purification techniques in extracorporeal circulation. In: Myśliwiec M (Ed.). Wielka Interna. $2^{\text {nd }}$ ed. Nephrology. Medical Tribune Polska, Warsaw 2017; 396-431.

6. Ciechanowski K. Assessment of kidney function. In: Myśliwiec M (Ed.) Wielka Interna. $2^{\text {nd }}$ ed. Nephrology. Medical Tribune Polska, Warsaw 2017; 20-31.

7. Kopeć J, Sułowicz W. Strategies of management in endstage renal failure. In: Scientific. Myśliwiec M (Ed.). Wielka Interna. $2^{\text {nd }}$ ed. Medical Tribune Polska, Warsaw 2017; 390-393.

8. Lizakowski S, Tylicki L. Hemodialysis - the most common method of extracorporeal cleansing. In: Rutkowski B (Ed.). Renal replacement therapy, a guide for patients and their families. Via Medica, Gdańsk 2010; 61-69.

9. Nowicki M. Choosing an optimal dialysis technique. Nephrological Forum 2010; 3: 121-126.

10. Aksamit D, Domański L, Durlak M, et al. Recommendations of the Working Group of the Polish Society of Nephrology on the quality criteria of dialysis treatment of patients with end-stage renal disease. Nephrol Dial Pol 2015; 19: 6-11.

11. Kasiske B, Wheeler D. KDIGO clinical practice guideline for the evaluation and management of chronic kidney disease foreword. Kidney International Supplements 2013; 3: 2.

12. Sułowicz W. Practical aspects of dialysis quality assessment. Nephrological Forum 2010; 3: 185-192.

13. Grajek ZW, Małyszko J, Małyszko J, et al. Assessment of the adequacy of dialysis measured with the Kt/ $\mathrm{V}$ index in patients dialysed with the use of a vascular access in the form of a telescopic arteriovenous fistula. Nefrol Dial Half 2009; 13: 143-147.

14. Ifudu O, Mayers JD, Mattew JJ, et al. Haemodialysis dose is independent of type of surgically-created vascular access. Nephrol Dial Transplant 1998; 13: 2311.

15. Liberek T, Rutkowski B, Weber E, et al. Tunneled catheters in dialysis - a boon or a necessary evil? Nephrology Forum 2015; 8: 205-213. 